\title{
Effect of Prophylactic Ondansetron on Norepinephrine Consumption for Spinal Anaesthesia induced Hypotension in Caesarean Section: A Prospective Study
}

\author{
Pratibha Jain Shah*, Pratiksha Agrawal and Rajesh Kumar Beldar \\ Department of Anaesthesiology and Critical Care, Pt JNM Medical College, India
}

Submission: March 15, 2019; Published: May 03, 2019

*Corresponding author: Pratibha Jain Shah, Professor and Head, Department of Anaesthesiology and Critical Care, Pt JNM Medical College, Raipur, India

\begin{abstract}
Background and Aim: Subarachnoid block are the preferred anaesthesia technique for caesarean section, but associated hypotension and bradycardia may be deleterious to both parturient and foetus. Activation of Bezold-Jarisch reflex (BJR) by decreased venous return to right heart stimulates 5-hydroxytryptamine type 3 (5HT3) receptors located in cardiac wall, leading to vasodilation, bradycardia and hypotension. Ondansetron (5-HT3 antagonist), a widely used antiemetic premedicant has been reported to reduce Spinal Anaesthesia Induced Hypotension (SAIH) and bradycardia. The aim of the present study was to assess the effect of prophylactic intravenous ondansetron on norepinephrine consumption used for treatment of SAIH following spinal anaesthesia for caesarean delivery.
\end{abstract}

Methods: Sixty-three parturients undergoing elective caesarean delivery under spinal anaesthesia were randomly allocated into two groups using chit system. Group-0 (n=21) received ondansetron $4 \mathrm{mg}$ and Group-M $(\mathrm{n}=42)$ received metoclopramide $10 \mathrm{mg}$ intravenously $5 \mathrm{~min}$ before spinal anaesthesia. During surgery $8 \mu \mathrm{g}$ norepinephrine bolus was given intravenously to manage hypotension. Blood pressure, heart rate, duration of surgery, consumption of norepinephrine and side effects were recorded.

Results: Demographically both groups were comparable. Consumption of norepinephrine in Group-M and Group-0 were $13.174 \pm 12.685 \mu \mathrm{g}$ and $18.857 \pm 15.4865 \mu$ g respectively and was statistically comparable $(\mathrm{P}=0.1933)$. There was no significant difference in adverse effects between both groups. Heart rate, systolic \& diastolic blood pressures were also comparable at all time intervals between both groups.

Conclusion: Premedication with intravenous ondansetron $4 \mathrm{mg}$ as compared to intravenous metoclopramide $10 \mathrm{mg}$ neither attenuates hypotension nor reduces consumption of norepinephrine significantly in parturients following spinal anaesthesia.

Keywords: Ondansetron; Norepinephrine; 5 Hydroxytryptamine; Spinal anaesthesia; Caesarean section; Hypotension

Abbreviations: Bezold Jarisch Reflex (BJR); Spinal Anaesthesia Induced Hypotension (SAIH); 5-hydroxytryptamine type 3 (5HT3); Blood Pressure (SBP); Diastolic Blood Pressure (DBP); Heart Rate (HR); American Society of Anaesthesiologists (ASA); Centimetre-cm; Kilogram-kg; Minute-min; Microgram- $\mu \mathrm{g}$

\section{Introduction}

Spinal anaesthesia is a referred technique for elective caesarean section due to its simplicity, ability to provide adequate surgical anaesthesia, higher maternal satisfaction, ease of administration, faster onset of action, and safety [1]. The incidence of maternal hypotension after spinal anaesthesia during caesarean delivery is as high as $50-80 \%$ [2] which can be detrimental to both mother and foetus. Many techniques \& various vasopressors have been tried and studied to manage hypotension following spinal anaesthesia, but no single method was found to be adequate or superior. Among the vasopressors (Ephedrine, Phenylephrine, Epinephrine and Mephentermine) none is conclusively better over the other $[3,4]$. Many studies

suggested that injection norepinephrine managed hypotension effectively with more stable hemodynamic profile than other vasopressor $[3,5]$.

5-HT is an important factor inducing Bezold-Jarisch Reflex (BJR) via 5-HT3 receptor located in intracardiac vagal nerve endings and cardiac wall. The BJR responds to noxious ventricular stimuli sensed by chemo receptors (5HT3 receptor) and mechanoreceptors within the ventricular wall of heart in the presence of decreased blood volume by inducing hypotension and bradycardia [6].

Ondansetron, a selective 5HT3 antagonist is widely used for the prevention and treatment of postoperative nausea \& vomiting. 
It has been demonstrated in various articles that prophylactic $4 \mathrm{mg}$ ondansetron injection alleviates hypotension in parturients undergoing caesarean delivery under spinal anaesthesia by antagonising 5-HT3 receptors \& blunting the BJR, but the results of these studies were not consistent [2,7-14].

Therefore, this prospective, double blind study was designed to prove or disprove our hypothesis that prophylactic intravenous ondansetron decreases incidence of spinal anaesthesia induced hypotension \& subsequent vasopressor requirement. Primary objective of the present study was to assess the effect of prophylactic intravenous ondansetron on norepinephrine consumption used for management of spinal anaesthesia induced hypotension and secondary objectives were effect on maternal Systolic Blood Pressure (SBP), Diastolic Blood Pressure (DBP), Heart Rate (HR), Apgar score and incidence of any adverse effects and complications.

\section{Material and Methods}

After approval from Institutional Ethics Committee and informed consent, 63 parturients between 18-35yrs of age, $50-100 \mathrm{~kg}$ weight, $140-180 \mathrm{~cm}$ height, American Society of Anaesthesiologists (ASA) physical status-II and singleton term pregnancy posted for elective caesarean delivery were enrolled for study from March 2018 to August 2018. Parturients with pre-existing pregnancy induced hypertension, cardiovascular or cerebrovascular disease, hepato-renal disease, gestational diabetes mellitus, allergy to study drugs, intraoperative use of uterotonic other than oxytocin, known foetal abnormality and contraindication to spinal anaesthesia were excluded from the study.

All participants were nil per oral for six hours prior to operation. On arrival to operation theatre, routine monitors were attached \& baseline HR, SBP, DBP, SpO2 \& ECG were recorded. A large wide-bore intravenous cannula was inserted into forearm. All participants were preloaded with $500 \mathrm{ml}$ ringer lactate. Parturients were randomly allocated into two groups by investigator through chit system to receive either ondansetron or metoclopramide. Parturients in Group-O ( $\mathrm{n}=21)$ received ondansetron $4 \mathrm{mg}$ and in Group-M (n=42) received metoclopramide $10 \mathrm{mg}$ intravenously $5 \mathrm{~min}$ prior to spinal anaesthesia to prevent nausea and vomiting. Study drug was taken in two $2 \mathrm{ml}$ identical syringes marked with a coded label of anti-emetic study drug, having either $2 \mathrm{ml}$ ondansetron $(4 \mathrm{mg}$ ) or $2 \mathrm{ml}$ metoclopramide (10mg). The anaesthesiologist, who administered anti-emetic study drugs, performed spinal anaesthesia and recorded the data for study, was blinded to patient's group.

Under all aseptic precautions, subarachnoid space was assessed through L3-L4 or L4-L5 intervertebral space using 25-gauge Quincke's spinal needle in left lateral decubitus position. After confirmation of free flow of cerebrospinal fluid, $2 \mathrm{ml}$ hyperbaric Bupivacaine $0.5 \%(\mathrm{w} / \mathrm{v}$ ) was administered in subarachnoid space. Then the parturient was made supine and $15^{\circ}$ to $20^{\circ}$ head tilt was given to facilitate block height. Once sensory block up to T6 or above dermatome level was achieved, surgery could start. HR, SBP \& DBP were recorded at every 2 min interval till 20 minutes $\&$ thereafter at every 5 min interval till completion of surgery. On each episode of hypotension (i.e. decrease in SBP to less than $80 \%$ of baseline value), $8 \mu \mathrm{g}$ bolus intravenous norepinephrine was administered. Bradycardia, a fall in HR below 50 per minute was treated with intravenous atropine $0.6 \mathrm{mg}$. Nausea, vomiting \& other maternal undesired effects were noted and managed accordingly. Neonatal assessment was done by Apgar score at $1^{\text {st }} \& 5^{\text {th }}$ minute.

Sample size was calculated as per data from Wang M, et al. [2] Efficacy of prophylactic intravenous ondansetron on prevention of hypotension during cesarean delivery: a dose -dependent study. Int J Clin Exp Med. 2014; 7(12):5210-5216; change in systolic blood pressure (Mean+SD) is $20.52+8.80$ [2]. Taking this into consideration, with the help of nMaster software (Single Mean-Estimating the population mean-Absolute precision) with absolute precision-5 and desired confidence level-99\% required sample size is 21 . Twenty-one subjects were considered as cases and 42 subjects as controls ( 2 controls for each case) and hence total 63 parturients were included for this study.

Statistical analysis was done by applying the unpaired student $t$ test to compare the means of two independent samples. P value $\leq 0.05$ was considered as significant and $P$ value $\leq 0.001$ as highly significant. Data were calculated with the help of Graph-pad in stat software.

\section{Results}

Table 1: Demographic profile, duration of surgery and level of block.

\begin{tabular}{|c|c|c|c|}
\hline Parameters & Group-0 & Group-M & p-value \\
\hline Age (years) Mean \pm SD & $24+3.8$ & $24+3.2$ & 0.9 \\
\hline Height (cm) Mean \pm SD & $153+5.05$ & $152+3.85$ & 0.23 \\
\hline Weight (kg) Mean \pm SD & $61.1+6.23$ & $61.2+3.21$ & 0.94 \\
\hline $\begin{array}{c}\text { Duration of Surgery (min) } \\
\text { Mean } \pm \text { SD }\end{array}$ & $43.67+2.972$ & $43.83+3.435$ & 0.85 \\
\hline $\begin{array}{c}\text { Level of sensory block(T4-5) } \\
\text { Number \& percentage }\end{array}$ & $17(81 \%)$ & $33(78.5 \%)$ & 0.8187 \\
\hline
\end{tabular}

Total 63 parturients scheduled for elective caesarean delivery were included in the study and used for analysis. There was no statistically significant difference in demographic data, height of sensory block and duration of surgery between both the groups (Table 1).

The baseline Heart Rate (HR) in Group-O and Group-M was $85 \pm 9.3$ beat $/ \mathrm{min}$ and $90 \pm 10$ beat $/ \mathrm{min}$ respectively and the difference was statistically non-significant $(\mathrm{P}=0.108)$. Post induction HR was also comparable within the group and between the groups till completion of surgery (Figure 1). The baseline systolic blood pressure (SBP) in Group-O and Group-M was $116 \pm 8.3574 \mathrm{mmHg}$ and $116.523 \pm 6.985 \mathrm{mmHg}(\mathrm{p}=0.2205)$. The baseline diastolic blood pressure (DBP) was $69.33 \pm 9.3879 \mathrm{mmHg}$ 
in Group-O and 71.5952 $\pm 5.151 \mathrm{mmHg}$ in Group-M ( $\mathrm{p}=0.9621)$. The difference in SBP and DBP was statistically non-significant. Post induction SBP and DBP were also comparable within the

group and between the groups till completion of surgery (Figure 2).
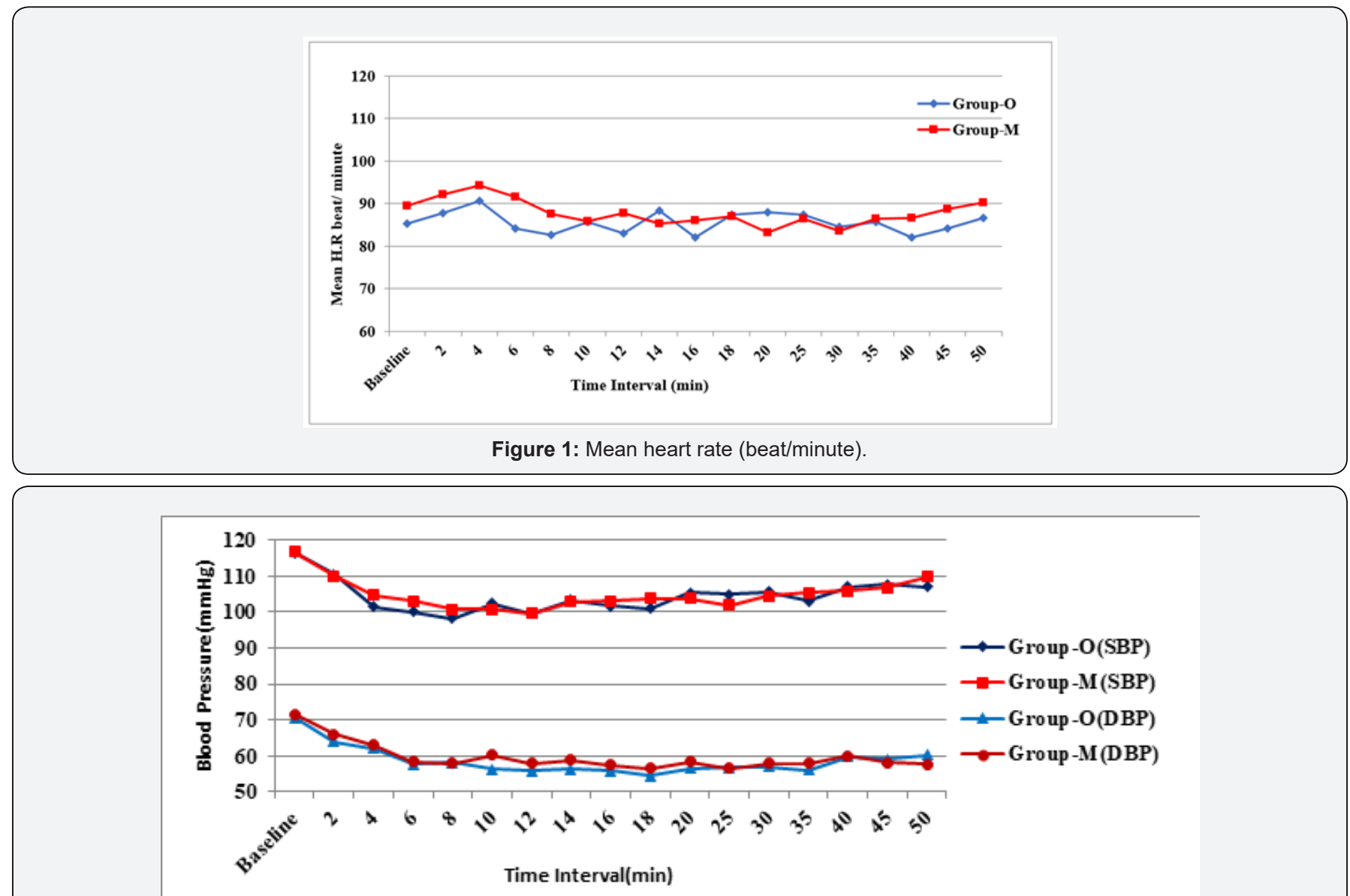

Figure 2: Mean systolic and diastolic blood pressure $(\mathrm{mmHg})$.

Both the groups had transient hypotension and treated with bolus of intravenous $8 \mu \mathrm{g}$ norepinephrine. Norepinephrine consumption was statistically non-significant between both the groups ( $p=0.1933)$ (Table 2). The differences in Apgar score at $1^{\text {st }}$ and $5^{\text {th }}$ minute between both the groups were statistically non-significant. (Table 2). Besides nausea/vomiting, shivering, bradycardia, hypotension and headache (difference in incidence was statistically not significant between the groups), no other adverse effects were observed in the study population (Table 3 ).

Table 2: Norepinephrine consumption \& Mean Apgar score.

\begin{tabular}{|c|c|c|c|c|}
\hline & $\begin{array}{c}\text { Group-0 } \\
(\text { Mean } \pm \text { SD })\end{array}$ & $\begin{array}{c}\text { Group-M } \\
(\text { Mean } \pm \text { SD })\end{array}$ & p-value \\
\hline \multirow{2}{*}{$\begin{array}{c}\text { Norepine-phrine } \\
\text { consumpt-ion }(\mu \mathrm{g})\end{array}$} & $13+12.69$ & $18.86+15.49$ & 0.1933 \\
\hline \multirow{2}{*}{$\begin{array}{c}\text { Apgar } \\
\text { score }\end{array}$} & 1 Min & $7.524+0.602$ & $7.714+0.673$ & 0.278 \\
\cline { 2 - 5 } & 5 Min & $9.66667+0.57735$ & $9.69048+0.51741$ & 0.869 \\
\hline
\end{tabular}

\section{Discussion}

Caesarean section under spinal anaesthesia is commonly associated with hypotension and bradycardia which can be detrimental to both the mother and the foetus. Vasodilatation following spinal anaesthesia leads to pooling of blood in periphery, relative hypovolemia \& subsequently decreased venous return. Insufficient blood return may trigger BJR by ventricular mechanoreceptors, further leading to bradycardia, vasodilation and hypotension $[6,15,16]$.

Table 3: Adverse effect \& complications.

\begin{tabular}{|c|c|c|c|}
\hline Side Effects /Complications & Group-0 & Group-M & p-value \\
\hline Nausea/Vomiting & $5(24 \%)$ & $11(26 \%)$ & 0.8645 \\
\hline Shivering & $2(9.5 \%)$ & $3(7.1 \%)$ & 0.7412 \\
\hline Bradycardia & 0 & $1(2.4 \%)$ & 0.4787 \\
\hline Hypotension & $12(57 \%)$ & $27(64 \%)$ & 0.5931 \\
\hline Total Spinal/High Spinal & 0 & 0 & - \\
\hline Headache & $1(4.8 \%)$ & $2(7.1 \%)$ & 0.726 \\
\hline Extrapyramidal Side Effects & 0 & 0 & - \\
\hline
\end{tabular}

Previously, various studies observed that prophylactic ondansetron injection alleviates hypotension in parturients undergoing cesarean delivery under spinal anaesthesia by antagonising 5-HT3 receptors \& blunting the BJR, but very limited study has been done to assess the effect of prophylactic 
ondansetron on consumption of norepinephrine [17]. Though various dosages of ondansetron were tried, $4 \mathrm{mg}$ of ondansetron preloading was found to be the optimal dose to prevent maternal hypotension and other adverse effects during caesarean delivery [2]. In our institute ondansetron $4 \mathrm{mg}$ or metoclopramide $10 \mathrm{mg}$ has been used to prevent nausea and vomiting secondary to spinal anaesthesia in caesarean section. Therefore, our primary outcome was to assess the effect of prophylactic intravenous $4 \mathrm{mg}$ ondansetron on norepinephrine consumption and secondary outcome was to observe the effect on maternal mean SBP, mean DBP, HR, Apgar score and incidence of adverse effects.

Mean consumption of norepinephrine in Group-O and Group-M was $13.174 \pm 12.685 \mu \mathrm{g}$ and $18.857 \pm 15.4865 \mu \mathrm{g}$, respectively ( $\mathrm{p}=0.1933)$. Karacaer $\mathrm{F}$ et al. [17] found significant reduction in mean consumptions of norepinephrine in ondensetron group $(22.6 \pm 19.5 \mu \mathrm{g}$ vs $35.7 \pm 25.8 \mu \mathrm{g}$; $\mathrm{p}=0.009)$. Our findings do not corroborate with those of Karacaer F et al. [17] who used $5 \mu$ g norepinephrine as rescue vasopressor and gave $8 \mathrm{mg}$ ondansetron prophylactically without fluid preloading. In our study preloading with $500 \mathrm{ml}$ ringer lactate was done, which might have prevented activation of BJR by maintaining blood volume in ventricles of heart. Thus, by avoiding hypotension, consumption of norepinephrine might have decreased during spinal anaesthesia [18].

HR, SBP \& DBP (baseline and after induction of spinal anaesthesia) were comparable within the group and between the groups till completion of surgery. Trabelsi W et al. [10], Karacaer F et al. [17] \& Terkawi AS et al. [19] have observed similar findings. Wang M et al. [2] found that reduction in HR, SBP and DBP from baseline were more in saline groups as compared to ondansetron group \& difference was statistically significant. This could be because they used phenylephrine $100 \mu \mathrm{g}$ as rescue vasopressor and coloaded with crystalloid. Sahoo T et al. [9] stated that fall in heart rate was more common in saline group as compare to ondansetron group but statistically significant fall was observed only twice at $24 \mathrm{~min}(\mathrm{P}=0.031)$ and at $45 \mathrm{~min}(\mathrm{P}=0.02)$. They used phenylephrine $50 \mu \mathrm{g}$ to treat hypotension.

The difference in mean Apgar score between both the groups was statistically non-significant. No significant difference in Apgar score was observed in the studies of Wang M et al. [2], Wang Q et al. [13], Karacaer F et al. [17] \& Terwaki AS et al. [19]. Hypotension was observed in $12(57 \%)$ parturients of ondansetron group compared to 27 (64\%) parturients in metoclopramide group which was statistically non-significant $(\mathrm{P}=0.5931)$. Karacaer $\mathrm{F}$ et al. [17] also found no significant difference in hypotension between the two groups $\{47 / 54(87 \%)$ in ondansetron group vs $48 / 54(88.9 \%)$ in saline group; $\mathrm{p}=0.767\}$. However cumulative episodes of hypotension were greater in group $\mathrm{S}(\mathrm{P}=0.009)$.

Bradycardia was statistically not significant in our study between both the groups ( $\mathrm{p}=0.4787)$. Sahoo $\mathrm{T}$ et al. [9], Wang $\mathrm{Q}$ et al. [13], Karacaer F et al. [17] \& Terwaki AS et al. [19] have observed similar findings. The incidence of nausea \& vomiting was statistically not significant between both groups $(\mathrm{p}=0.8641)$. Karacaer $\mathrm{F}$ et al. [17] have observed similar findings. Wang $\mathrm{M}$ et al. [2], Sahoo T et al. [9] \& Wang Q et al. [13] found significantly low incidence of nausea/vomiting in ondansetron group. There are some limitations of our study:

a) The occurrence of hypotension, bradycardia and consumption of norepinephrine were not compared with the administration of ondansetron alone.

b) Different definition of hypotension and bradycardia in various studies in parturients undergoing caesarean section under spinal anaesthesia affects the incidence of hypotension and makes it difficult to compare the results.

c) We studied ondansetron only at its $4 \mathrm{mg}$ dose.

d) Larger study group is needed to evaluate the effect of ondansetron on consumption of vasopressors. The effect of various doses of ondansetron on attenuation of hypotension in caesarean delivery in spinal anaesthesia with preloading and coloading of crystalloid in larger population can be studied in future [20].

\section{Conclusion}

Premedication with intravenous 'ondansetron $4 \mathrm{mg}$ as compared to metoclopramide 10mg' neither attenuates hypotension nor reduces consumption of norepinephrine significantly in parturients after spinal anaesthesia in caesarean delivery.

\section{References}

1. Gandhi KA, Jain K (2018) Management of anaesthesia for elective, lowrisk (Category 4) caesarean section. Indian J Anaesth 2018; 62(9): 667674.

2. Wang M, Zhuo L, Wang Q, Shen MK, Yu YY, et al. (2014) Efficacy of prophylactic intravenous ondansetron on prevention of hypotension during cesarean delivery: a dose -dependent study. Int J Clin Exp Med $7(12): 5210-5216$.

3. Ngan Kee WD (2017) A random allocation graded dose response study of Norepinephrine \& Phenylephrine for treating hypotension during spinal anaesthesia for cesarean delivery. The ASA, Anaesthesiology 127(6): 934-941.

4. Gupta S, Sharma SP (2017) Comparative study of Phenylephrine, Ephedrine and Mephentermine for treatment of hypotension during spinal anaesthesia for caesarean section. IJSR 6(4): 2277-8179.

5. Ngan Kee WD, Lee SW, Ng FF, Tan PE, Khaw KS (2015) Randomized double-blinded comparison of norepinephrine and phenylephrine for maintenance of blood pressure during spinal anesthesia for cesarean delivery. The ASA, Anaesthesiology 122(4): 736-745.

6. Campagna JA, Carter C (2003) Clinical relevance of the Bezold Jarisch reflex. Anesthesiology 98(5): 1250-1260.

7. El Khouly NI, Meligy AM (2016) Randomized controlled trial comparing ondansetron and placebo for the reduction of spinal anesthesia induced hypotension during elective cesarean delivery in Egypt. Int J Gynaecol Obstet 135(2): 205-209.

8. Owczuk R, Wenski W, Twardowski P, Dylczyk Sommer A, et al. (2015) Ondansetron attenuates the decrease in blood pressure due to spinal anesthesia in the elderly: a double blind, placebo-controlled study. Minerva Anestesiol 81(6): 598-607. 
9. Sahoo T, Sen Dasgupta C, Goswami A, Hazra A (2012) Reduction in spinal-induced hypotension with ondansetron in parturients undergoing caesarean section: A double blind randomised placebo- controlled study. International Journal of Obstetric Anesthesia 21(1): 24-28.

10. Trabelsi W, Romdhani C, Elaskri H, Sammound W, Bensalah M, et al. (2015) Effect of Ondansetron on the occurrence of Hypotension and on Neonatal Parameters during Spinal Anesthesia for Elective Caesarean Section: A Prospective, Randomized Controlled Double-Blind Study. Anesthesiol Res Pract 2015: 158061.

11. Zhou C, Zhu Y, Bao Z, Wang X, Liu Q (2018) Efficacy of ondansetron for spinal Anesthesia during cesarean section: a meta-analysis of randomized trials. J Int Med Res 46(2): 654-662.

12. Gao L, Zheng G, Han J, Wang Y, Zheng J (2015) Effects of prophylactic ondansetron on spinal Anesthesia-induced hypotension: a meta-analysis. Int J Obstet Anest 24(4): 335-343.

13. Wang Q Zhuo L, Shen MK, Yu YY, Yu JJ, et al. (2014) Ondansetron Preloading with Crystalloid Infusion Reduces Maternal Hypotension during Cesarean Delivery. Am J Perinatol 31(10): 913-922.

14. Tubog TD, Kane TD, Pugh MA (2017) Effect of Ondansetron on Attenuating Spinal Anesthesia-Induced Hypotension and Bradycardia in Obstetrics and nonobstetric Subjects: A Systemic Review and Meta-Analysis. AANA Journal 85(2): 113-122.

15. Warltier DC, Campagna JA, Carter C (2003) Clinical Relevance of the Bezold-Jarisch Reflex. Anesthesiology 98: 1250-1260.

This work is licensed under Creative Commons Attribution 4.0 License

DOI: 10.19080/JAICM.2019.08.555750
16. Heesen M, Klimek M, Hoeks SE, Rossaint R (2016) Prevention of Spinal Anesthesia-induced Hypotension During Cesarean Delivery by 5-Hydroxytryptamine-3 Receptor Antagonists: A Systematic Review and Meta-analysis and Meta-regression Obstetric. Anesth Analg 123(4): 977-988.

17. Karacaer F, Biricik E, Ünal İ, Büyükkurt S, Ünlügenc H (2018) Does prophylactic ondansetron reduce norepinephrine consumption in patients undergoing cesarean section with spinal anesthesia? Journal of Anesthesia. J Anesth 32(1): 90-97.

18. Garg R, Goila A, Pawar M (2011) Catastrophic complication BezoldJarisch reflex: Case series. Indian J Anaesth 55(6): 627-628.

19. Terkawi AS, Tiouririne M, Mehta SH, Hackworth JM, Tsang S, et al. (2015) Ondansetron Does Not Attenuate Hemodynamic Changes in Patients Undergoing Elective Cesarean Delivery Using Subarachnoid Anesthesia: A Double-Blind, Placebo-Controlled, Randomized Trial. Regional Anesthesia and Pain Medicine 40(4): 344-348.

20. Ortiz Gomez JR, Palacio Abizanda FJ, Morillas Ramirez F, Fornet Ruiz I, Lorenzo Jimenez A, et al. (2017) Reducing by 50\% the incidence of maternal hypotension during elective caesarean delivery under spinal anesthesia: Effect of prophylactic ondansetron and/or continuous infusion of phenylephrine: A double-blind, randomized, placebo-controlled trial. Saudi J Anaesth 11(4): 408-414.

\section{Your next submission with Juniper Publishers} will reach you the below assets

- Quality Editorial service

- Swift Peer Review

- Reprints availability

- E-prints Service

- Manuscript Podcast for convenient understanding

- Global attainment for your research

- Manuscript accessibility in different formats

( Pdf, E-pub, Full Text, Audio)

- Unceasing customer service

Track the below URL for one-step submission

https://juniperpublishers.com/online-submission.php 